\title{
Perceived Discontinuities and Continuities in Transdisciplinary Scientific Working Groups
}

\author{
Kevin Crowston ${ }^{\mathrm{a}}$, Alison Specht ${ }^{\mathrm{b}}$, Carol Hoover ${ }^{\mathrm{c}}$, Katherine M. Chudoba ${ }^{\mathrm{d}}$ and Mary \\ Beth Watson-Manheim ${ }^{\mathrm{e}}$
}

${ }^{a}$ School of Information Studies, Syracuse University, and National Science Foundation, United States of America.

${ }^{\mathrm{b}}$ Australian Centre for Ecological Analysis and Synthesis, Terrestrial Ecosystem

Research Network, University of Queensland, Australia

${ }^{c}$ Research Library, Los Alamos National Laboratory, US Department of Energy, United States of America.

${ }^{\mathrm{d} J o n}$ M Huntsman School of Business, Utah State University, United States of America. ${ }^{\mathrm{e}}$ Department of Information and Decision Sciences, University of Illinois at Chicago, United States of America. 


\section{Perceived Discontinuities and Continuities in Transdisciplinary Scientific Working Groups}

\section{INTRODUCTION}

Transdisciplinary scientific teams are created to advance innovative scientific endeavors when it is necessary to synthesize scientific information, whether to inform policy development or create infrastructure platforms to support continued advances in science. Research suggests that such teams can be more productive (Hall et al., 2012a) and creative (Kaufmann et al., 2009) than conventional research teams. However, to be successful, such teams must be able to draw on diverse bodies of expertise, knowledge and experiences (Edmondson, 2002).

One solution to staffing such a team is to hire a small number of full-time experts to address the problem. However, it can be difficult to find individuals with the necessary expertise who are willing and able to join what might be a short-term project. An alternative is to create a working group, that is, an ad hoc group of unpaid subject-matter experts who work together outside their main employment/jobs to achieve specified goals (Lee et al., 2006). For example, in an undirected manner, a working group model was used as the modus operandi at the Australian National Centre for Ecological Analysis and Synthesis (NCEAS) (Hampton and Parker, 2011). At NCEAS, groups of 8-15 collaborators from several scientific disciplines relevant to a research question they all wish to solve meet face-to-face several times a year over several years, linked by periods of remote collaboration. These working groups have proved to be successful in catalyzing publications with high citation rates (Hampton and Parker, 2011; Rodrigo et al., 2013).

The use of a voluntary collaborative model in this manner to achieve specified goals is full of risk, however, as its success as a team is dependent on shared vision, a willingness to collaborate, and outcomes that may not be anticipated by the organisation using the working group as an organisational model. Team members are usually selected for their expertise, and this selection will necessarily bring many differences in organisation, discipline and distance that may create boundaries between members. To be successful, team members must collaborate across these boundaries, often without the luxury of time to build consensus understandings (Lindkvist, 2005). A further complication is that working group members are often multi-teaming, as participation in 
the working group is not their only responsibility: they are concurrently members of the working group and members of teams in their home organisations (Mortensen et al., 2007).

Achieving integration across boundaries is problematic. Conflicts often increase (Griffin and Hauser, 1996; Hinds and Mortensen, 2005) and communication problems arise when transmitting information across the boundaries between different domains (Beverland, 2005; Carlile, 2002; Hauser et al., 2006). Perhaps as a result, findings from research on the link between integration in new product development teams (often organized as a kind of working group) and innovative outcomes have been equivocal, with the link found to be positive, negative or non-existent (Nakata and Im, 2010). We interpret this evidence as suggesting that some working groups are able to capitalize on the diverse knowledge and background of their members, but that others are not. Consideration of the apparent mixed success in addressing these inherent challenges raises several questions that we address in this paper:

1. What are the strengths and weaknesses of the working group model of organisation for transdisciplinary scientific teams?

2. What do participants gain from being involved in a project as a member of a working group?

3. What does a project gain from member involvement (i.e. how effective is the working group model as a management tool)?

Past work on the working group model has identified a number of factors that may be relevant for their success. For example, Hampton and Parker (2011) found that the number of meetings, rather than duration of each meeting, was the most significant positive effect on productivity as measured by publications. Productivity was related not just to the duration of a meeting but also to more complex sociological within-group effects, such as group size (negative), cross-institutional representation (positive) and inclusion of dedicated sabbatical fellows (positive). Face-to-face meetings in a neutral location were instrumental in developing the trust and communication efficiency that accelerated idea generation.

In this paper, we further explore these factors and provide an integrative model by applying organisational discontinuity theory, a model proposed by Watson-Manheim et al. (2012) concerning the effects of boundaries on work. As noted above, boundaries between team members are usually seen as a source of difficulties, but this model 
suggests that they need not always be problematic. The model suggests that boundaries are problematic only to the extent that members experience difficulty in communication and accomplishing their work, an outcome the theory calls a 'discontinuity'.

Contrariwise, if members of the team recognize a problem with communication or a work process, they may adapt their actions to create shared routines and mental models (a continuity) and thus mitigate the problems. Adapting processes and practices across boundaries to integrate the varied knowledge and experience of team members is likely to maximize the speed and productivity of the process to create desired outcomes.

To illuminate the role of discontinuities and continuities in the success of working groups for transdisciplinary integration, we examine DataONE, a transdisciplinary scientific team tasked with creating a 'cyberinfrastructure platform to support rapid data discovery and access across diverse data centers distributed worldwide and to provide scientists with an integrated set of familiar tools that support all elements of the data life cycle' (Michener et al., 2012). Its objective was a difficult one to achieve, requiring innovative solutions. The DataONE project used a working group structure to organize input from a wide range of experts.

The paper is organized as follows. We begin by briefly reviewing the literature on management of scientific teams, drawing on the emerging literature on the 'science of team science'. We then describe organisational discontinuity theory, the theoretical lens we use to focus our investigation. In the following section, we describe DataONE and its working group structure, a structure often used by transdisciplinary scientific groups. We then present our study approach, followed by the results of participant observation, quantitative and qualitative data. Finally, we offer recommended best practices for other transdisciplinary scientific groups.

\section{THEORY DEVELOPMENT: ORGANISATIONAL DISCONTINUITIES AND THE PROBLEMS OF TRANSDISCIPLINARY RESEARCH}

There is an extensive and growing body of research on the 'science of team science' (e.g. Stokols et al., 2010) that examines how research groups form, work and succeed. Börner et al. (2010) state that the 'field is concerned with understanding and managing circumstances that facilitate or hinder a range of collaborative research efforts'. Research on science of team science covers a wide range of topics, with research 
conducted at multiple levels of analysis, from the individual member to the group to the organisational and institutional setting. Falk-Krzesinski et al. (2011) solicited team science research topics from researchers and practitioners to identify clusters of research topics comprising a science of team science research agenda. Their analysis identified clusters around measurement and evaluation of team science; structure and context for teams; characteristics and dynamics of teams; management and organisation for teams; institutional support and professional development for teams; disciplinary dynamics and team science; and definitions and models of team science.

Research teams can include members from different disciplinary configurations, but much of the research on the science of team science has examined multidisciplinary or interdisciplinary teams, often with the goal of developing a transdisciplinary approach to a complex research topic. Such teams can be particularly problematic to manage since they often involve multiple nested goals (e.g. scientific inquiry, educational goals, translation to practice, translation to policies) with divergent logics of action (Winter and Berente, 2012). Teams may be situated in one or more organisations with full-time participants, or more comparable to the part-time participation of working groups.

Much of the research has come from organisations that sponsor science teams and as such has been pragmatically driven, aiming at identifying factors for team success (e.g. Vogel et al., 2014). For example, Lotrecchiano (2013) took a social psychological perspective on team performance, looking at interaction of micro and meso-behaviours, identifying issues such as team familiarity and social cohesion; leadership traits and behaviors; goal setting; and dynamism in reciprocal interdependence. Based on a grounded theory analysis, Lotrecchiano (2013) identified four social mechanisms that dominated the analysis of social dynamics and mechanisms within a transdisciplinary team - change, kinship, tension, and heritage. Stokols et al. (2008) identified a range of factors including team members' familiarity and social cohesiveness; team size and physical environmental conditions; leadership traits and behaviors; participatory goal setting and communication patterns; and task and outcome interdependence. For distributed teams they identified additional factors such as the availability of adequate infrastructure, the difficulty of working across time zones, as well as socio-cognitive and emotional factors such as trust. 
To address these factors, researchers have developed a range of advice for those managing or involved in science teams, e.g. tools for assessing potential team members' readiness for collaboration (Hall et al., 2008), a toolkit of advice on team science (Vogel et al., 2013), scales for measuring collaboration and integration (Mâsse et al., 2008), team charters (Asencio et al., 2012) and a 'Collaboration Success Wizard' (Bietz et al., 2012).

Our goal in this paper is to contribute to the body of research on science of team science by providing an holistic perspective on transdisciplinary scientific working groups that explains the difficulties group members face and their possible responses from a common principle, namely organisational discontinuities.

Organisational Discontinuity Theory

Organisational discontinuity theory provides a perspective for analyzing the problems encountered by members of teams who must span various boundaries in the course of getting their work done: boundaries of place, organisation, discipline and so on. Boundaries are important because they distinguish one domain or situation from another, ordering and simplifying the environment (Ashforth et al., 2000; Schneider, 1987; Schreyögg and Sydow, 2010). For example, knowing that someone is from one's own institution may make it easier to know how to contact and work with him or her.

On the other hand, boundaries are also points where differences between team members become salient and potentially problematic. Prior research has found that working across geographic boundaries may increase conflict (Hinds and Mortensen, 2005) and miscommunication (Cramton, 2001). The problems faced when working across boundaries are not due simply to the demarcations separating the different subgroups but rather to the differences in actions, attitudes, and expectations (Levina and Vaast, 2006; Maznevski and Chudoba, 2000; Mortensen et al., 2007). For example, individuals from different disciplines may use different terminology, consider different kinds of data more important, or deem different kinds of analyses more valid. Carlile (2002) noted that such barriers can be syntactic (different formats of information), semantic (different groups assign different meanings to information) or pragmatic (different groups have different practices or interests). As an example of a semantic barrier, Bresnen et al. (2003) found that teams with members from different professions faced difficulties in applying knowledge because to do so required 'a shared system of 
meaning for understanding, accepting and deploying it'. As an example of a pragmatic barrier, Scarbrough et al. (2004) identified 'learning boundaries', where differences in practices between parts of an organisation posed barriers to sharing learning from projects.

Nevertheless, boundaries are not uniformly or even necessarily problematic. Organisational discontinuity theory argues that a boundary becomes problematic when an individual perceives a change in information and communication flows that requires conscious effort and attention to handle (Watson-Manheim et al., 2012). We define this disruption as a discontinuity. But working across a boundary need not necessarily lead to a discontinuity. Similar to dormant faultlines, or demographic differences among group members that have the potential to create conflict but are not always activated (Lau and Murnighan, 1998), boundaries may exist but may not lead to discontinuities between group members. If flows of communication and action are as expected or require minimal attention and effort to manage, then the situation is perceived as normal, i.e. a discontinuity is not present (Watson-Manheim et al., 2012).

Boundaries are highly likely in scientific working groups, as they are often created specifically to encourage a diversity of input from disparate members in order to develop novel ideas and perspectives. Discontinuities stemming from these boundaries, e.g. from different locations, work practices, priorities and culture members bring from their home organisations, have created challenges for members of innovation teams (Leonardi, 2011) and in academic-industry partnerships (Dixon and Panteli, 2010).

When faced with a discontinuity, that is, with a disruption in the expected flow of communication, individuals must make sense of the disruption and address the problem. This extra effort may prompt them to vary their actions to reduce discomfort surrounding the situation (George and Jones, 2001). They may be motivated to pay more attention to the situation and consider alternative actions to deal with the discontinuity, leading to the emergence of new behaviors and expectations. In many cases, members of teams dispersed across boundaries, including those involved with problems requiring innovative solutions, are able to adapt their processes over time to span these differences (Bjørn and Ngwenyama, 2009; George and Jones, 2001; Orlikowski, 2002). Thus, a corollary to discontinuities is the emergence of continuities that reduce or eliminate the attention and 
effort required to understand and manage the situation associated with problematic boundaries (i.e. discontinuities) (Dixon and Panteli, 2010; Watson-Manheim et al., 2012).

As a very simple example, having group members in multiple time zones may initially lead to problems scheduling group meetings, e.g. setting a meeting time but forgetting to specify the time zone, resulting in people misinterpreting the intended time. However, after a few false starts, the group members can develop practices that help to manage differences, e.g. specifying the time and time zone separately for each member when scheduling meetings. But if a new member from a very different time zone is added, new problems may emerge, such as finding overlaps in time for the group meeting. The time zone differences create a discontinuity that again requires the attention of the group members and likely a change in meeting scheduling practices.

Continuities can be created through deliberate management, group member intervention, or emerge as members work through problems arising from the presence of discontinuities. Some pre-existing boundaries provide the means for continuity to emerge, such as members with previous marketing experience banding together to form an $a d$ hoc team to address new issues that required marketing expertise (Dixon and Panteli, 2010). However, a change in behavior only leads to a continuity when it is repeated over time because it resolves problems triggered by perceptions of the discontinuity. The work group dealing with time zone differences may try several different actions to manage the differences; the group is likely to repeat the practice that seems to best manage the problem, i.e. specifying local times and time zones for all members. The repetition of actions leads to expected patterns of behavior and a new norm in work practices is created (Feldman and Pentland, 2003). Individuals may be willing to repeat the new behavior for some time even if it does not immediately achieve the desired results, perhaps making minor modifications over time in search of a solution. If, however, the change in behavior does not lead to the expected results or a positive outcome, then individuals may try something else or alternatively, revert back to their prior work practices and thus not form a continuity.

Through the lens of organisational discontinuity theory, we can restate our first research questions more precisely as:

1. What kinds of discontinuities do transdisciplinary scientific teams face? 
2. What kinds of continuities do team members develop that are helpful in addressing these discontinuities?

\section{SETTING: THE 'DATAONE' (DATA OBSERVATION NETWORK FOR EARTH) PROJECT \\ Our study is set in the context of the 'DataONE' (Data Observation Network for}

Earth) project, which is designed to develop and deploy a sustainable long-term data preservation and access network, to ensure the preservation and access to multi-scale, multi-discipline, and multi-national environmental and biological science data (https://www.dataone.org/what-dataone; Michener et al., 2012). It was established in 2009 with funding from the United States National Science Foundation (NSF) and from mid-2014 commenced its second phase (Figure 1).

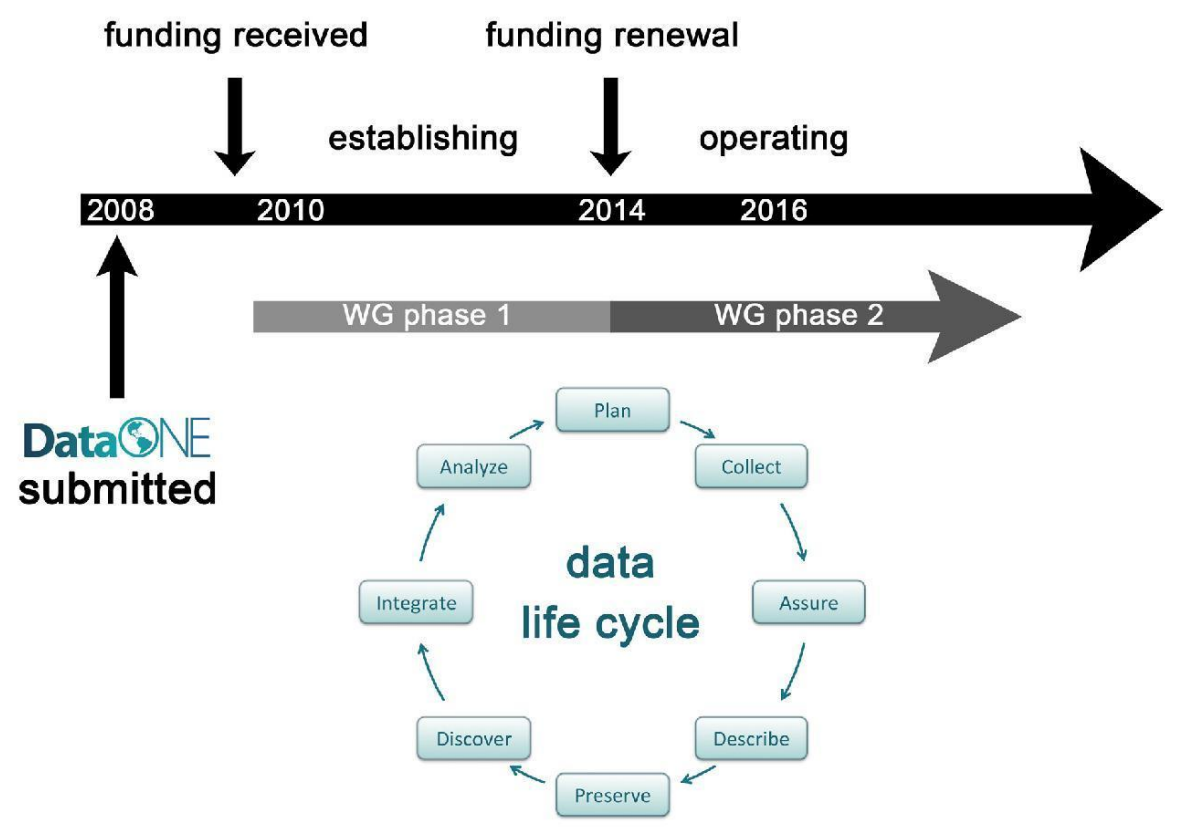

Figure 1. Key events in DataONE history and the Working Group phases. The DataONE data lifecycle is extracted from Figure 7, Michener et al. (2012).

The project has several unique features: (i) it was designed to expand on existing infrastructure, (ii) it had a global mandate to offer tools and solutions that would promote science and knowledge-creation, and (iii) it needed to facilitate evolving communities of practice based around the ever-developing cyberinfrastructure and the use of it (Michener et al., 2012). The DataONE mandate was daunting: the environmental and biological science community is notoriously diverse with great variation in scales, discipline paradigms and data types, alongside substantial organisational and geographical diversity. 
To achieve its goal required some innovative solutions to deliver a product that was usable and inter-operable across a wide range of disciplines including environmental, computer and human sciences. DataONE adopted working groups as a method for organizing targeted research and education activities, and engaging with the stakeholder community (Michener et al., 2012). The working group model was designed to allow DataONE to work with a broader group of scientists and users than would otherwise have been possible, providing a deeper experience and hence input than consultative meetings alone, and to enable such activities to evolve over time.

In addition to the Leadership team and the Cyberinfrastructure team, both largely comprised of employed staff, nine working groups were supported, roughly corresponding to the DataONE deliverables. These were (i) Data preservation and metadata, (ii) Community education and engagement, (iii) Scientific workflows and provenance, (iv) Data integration and semantics, (v) Scientific exploration, visualisation and analysis, (vi) Sociocultural issues, (vii) Public participation in science and research, (viii) Sustainability and governance, (ix) Usability and assessment. For the purposes of this paper, all these groups are referred to as working groups.

Each working group organized the activities and proposed solutions to particular research, education, and cyberinfrastructure problems on which the team members worked, based on a charter that broadly outlined its tasks. As an example, the purpose, scope and mission of the Usability and Assessment Working Group included:

- a focus on the research, development, and implementation of the necessary processes, systems, and methods to [ensure] DataONE products and services meet network goals, include appropriate community involvement, and demonstrate progress and achievements of DataONE,

- activities necessary to establish program performance indicators, measure usage and impact, and adopt usability analysis principles and methods to ensure that high quality, community-driven products and services result from DataONE activities, including periodic testing of versions of the system and tools as they are being developed, and

- baseline and ongoing assessment of data practices and opinions of DataONE stakeholders (Usability and Assessment Working Group Charter, May 2010).

As another example, the Sociocultural Issues working group was tasked with understanding non-technical factors that might maximize or hinder the impact of the DataONE repository (e.g. scientists' attitudes towards data sharing that discourage use of the systems). More information on responsibilities of working groups can be found 
at the DataONE Working Group web page (https://www.dataone.org/working_groups).

Each working group had two co-leaders, and up to twenty members from diverse relevant expert communities. The DataONE Principal Investigator and core management team (around ten members) and representatives from each of the eleven working groups formed the leadership for the project as a whole. The members of each Working Group were nominated by the working group co-leads and approved by the leadership team. The project PI described the groups as being selected to include specialists in informatics, computer science, domain scientists and librarians, chosen for expertise related to systems development, scientific data management as well as education and outreach.

With the exception of the Principal Investigator, Professor Michener, core DataONE staff (e.g. key project executives, developers and post doctoral students) are full-time and paid. A middle level of participants get some support for their time (e.g. the working group leads). However, the majority of working group members are paid only a small honorarium and expenses for their attendance at meetings.

During the first phase between May 2010 and May 2014, working group activity followed a consistent pattern. Activity was punctuated by twice-yearly meetings: the 'All Hands' meeting at which all working groups participated, and another meeting with the groups alone, sometimes in collaboration with another. Collaboration between meetings was arranged by the co-leads or supporting postgraduate staff, and usually consisted of teleconference and other on-line meetings.

The DataONE project provides a good opportunity to reflect upon the strengths and weaknesses of the working group model for transdisciplinary synthesis using the lens of organisational discontinuity theory. The effectiveness of these groups to achieve the end purpose of DataONE depended on several things, including relevance of the skill-sets and expertise brought to bear through the groups, their harmonious operation, and their direction and productivity. The use of working groups created an in situ set of boundaries, some of which were likely to be perceived as problematic - i.e. discontinuities - by team members. Having more people involved provided a needed diversity of skills, but this diversity meant there were more people across which knowledge needed to be synthesized. The episodic nature of the interactions fit the limited time that most participants had to devote to the project but raised problems of engagement between 
meetings. The majority of participants had little inherent incentive, it would seem, to contribute to DataONE beyond a belief in its goals and the development of a sense of worth through their participation, as they were not paid to attend, nor was this a direct part of their normal working life. Unlike the NCEAS and other synthesis centers' use of the working group model as a tool, there were few certain outcomes of value for an academic's career, such as publications. Nevertheless, the success of DataONE suggests that working groups were able to develop continuities to resolve these potential discontinuities.

\section{METHODS}

The research presented in this paper follows an approach called participatory and appreciative action and reflection (PAAR) (Ghaye et al., 2008). This approach is not centered on solving problems, but on understanding why aspects of our work are indeed successful, and how these can be amplified and made more consistent. PAAR is allied to participative reflection and brings together action and reflection with the participation of a range of stakeholders, and embraces the idea of reflective learners as skillful ethical decision-makers. This approach is congruent with the expectations in DataONE's charter that working group members would collaborate on knowledge generation activities such as research publications and patents in order to inform the project, and disseminate what was learned from the project.

Three of the authors were members of two DataONE working groups for four years. Specht is an academic and environmental scientist, Hoover is a research librarian in an organisation that employs many engineers and scientists, and Crowston is an academic with expertise in team processes. After their experience in the early years of the project, these authors recognized that lessons could also be learned about interdisciplinary collaboration that would benefit other transdisciplinary scientific working groups and obtained IRB approval for data collection in years 4 and 5 . In year 5 two non-DataONE researchers, Chudoba and Watson-Manheim, joined the team to provide additional expertise in team processes and in order to triangulate their observations with those of embedded researchers.

Data for the research were gathered in multiple ways, reflecting the mixed method approach of PAAR. 
1. Participant observation as group members throughout the course of the project;

2. Surveys in 2013 and 2014; and

3. In-depth interviews in 2014.

First, participant observation during the first two years of participation in the DataONE community led to a range of reflective, appreciative questions. These were explored with other members of the DataONE community in informal presentations and discussions.

The observations and responses to discussions led to the development of more systematic surveys carried out in October 2013 and May 2014 (the second approach to data collection). Survey questions were framed around two themes: (i) feedback about involvement with DataONE through the working group process, and (ii) comments about the effective use of the working groups. Survey questions are included in an Appendix.

Links to electronic versions of the surveys were emailed to the DataONE email distribution list during 2013 and 2014 'All Hands' meetings. While the majority of DataONE participants attended the 'All Hands' meetings, use of the email distribution list meant that those who could not attend also had an opportunity to provide feedback. Reminder announcements to complete the surveys were made to individual working groups, as well as verbally during gatherings that included all participants. The 2014 survey was timely, in that the success of the DataONE project was formally announced just prior to administration of the survey, and the change to the number of working group (from eleven to two) was confirmed.

Response rates for the surveys can not be determined precisely because the email list used for distributing the surveys included former DataONE participants who no longer worked with the project, sometimes with invalid email addresses, and failed messages were returned to a member of the DataONE staff, not the researchers on this project. A conservative estimate is that a minimum of $35 \%$ of participants responded to each of the two surveys. Because responses were submitted anonymously and the different surveys collected different demographic data, it is not possible to accurately determine the presence of response bias across working groups.

Third, the two non-DataONE researchers conducted interviews with four participants early in 2014, before the 'All Hands' meeting. Some were conducted Faceto-Face and others over the telephone. One person conducted the interview and the other 
took extensive notes. One of the non-DataONE members attended the 2014 'All Hands' meeting, observed individual working group meetings and conducted informal interviews. Extensive notes were taken about interactions between participants, focusing on areas that appeared to demonstrate the presence of either discontinuities or continuities.

Throughout data collection, the researchers met to discuss their observations and make sense of the data (Denzin and Lincoln, 2002). Analysis of qualitative data included comparing insights across sources (e.g. FTF observation, interviews, responses to openended questions on surveys), and using these insights to guide the development of subsequent interview and survey questions. Qualitative data were placed into an Excel spreadsheet, and pattern matching across words and phrases (e.g. axial coding) was done to identify common themes. Each respondent was given a unique code for reporting. Quantitative data were collated and summarised, and frequencies, means and standard errors calculated and graphed as relevant. For suitable variables, analysis of variance was conducted using the Statistical Package for the Social Sciences (SPSS@).

\section{RESULTS}

In this section, we present quantitative data collected from surveys administered in years 4 and 5 of the DataONE project (2013 and 2014).

\section{Situational variables}

The characteristics of DataONE members obtained through their responses to the questionnaires indicate the presence of several boundaries. Respondents were mainly established in their careers $(40 \pm 2 \%)$, with a smaller proportion in training $(9 \pm 1.1 \%)$, starting $(20 \pm 0.4 \%)$ or towards the end of their careers $(29 \pm 1.4 \%)$. This bias towards senior members provided a wealth of experience to DataONE's activities. A wide range of disciplines and job titles were represented among working group members (Table 1). Interestingly, more than 28 percent of the membership earned their primary degree in information or library science (column 1), and most were managers, researchers or faculty (column 2). The majority of participants worked in universities or research institutions (column 3). Although there were working group members from business or non-government organisations, none responded to the surveys in 2013 and 2014. The greater majority of respondents were from the United States of America (column 4). Of 
these, most were from the eastern states reflective of the partners in DataONE: the University of Tennessee and Oakridge National Laboratory both based near Knoxville, NCEAS and the California Digital Libraries in California, and of course the University of New Mexico, where the Principal Investigator is based.

Table 1. Situational variables based on respondent feedback (content within rows are not correlated).

\begin{tabular}{|c|c|c|c|c|c|c|c|}
\hline $\begin{array}{l}\text { 1. Primary } \\
\text { Degree }\end{array}$ & (\%) & 2. Job Title & $(\%)$ & 3. Work Sector & (\%) & $\begin{array}{l}\text { 4. Location } \\
\text { (with time } \\
\text { zone for } \\
\text { USA) }\end{array}$ & (\%) \\
\hline $\begin{array}{l}\text { Information } \\
\text { science / librarian }\end{array}$ & 28.4 & $\begin{array}{l}\text { Administrator / } \\
\text { manager }\end{array}$ & 19.0 & $\begin{array}{l}\text { University or } \\
\text { Research-only } \\
\text { Institution }\end{array}$ & 76.70 & $\begin{array}{l}\text { United States } \\
\text { of America }\end{array}$ & 92.3 \\
\hline $\begin{array}{l}\text { Biologist / } \\
\text { ecologist / life } \\
\text { sciences }\end{array}$ & 25.7 & $\begin{array}{l}\text { Researcher / } \\
\text { Scientist }\end{array}$ & 19.0 & $\begin{array}{l}\text { Local / State / } \\
\text { Federal } \\
\text { Government }\end{array}$ & 19.42 & Eastern & 58.5 \\
\hline Computer scientist & 16.5 & $\begin{array}{l}\text { Faculty member } \\
\text { (tenured) }\end{array}$ & 17.2 & $\begin{array}{l}\text { Not for Profit } \\
\text { Organisation }\end{array}$ & 2.91 & Central & 3.7 \\
\hline Engineering & 6.4 & $\begin{array}{l}\text { Faculty member } \\
\text { (untenured) }\end{array}$ & 10.3 & Publisher & 0.97 & Mountain & 19.5 \\
\hline $\begin{array}{l}\text { Spatial scientist / } \\
\text { geographer }\end{array}$ & 2.8 & $\begin{array}{l}\text { Technical } \\
\text { staff/software } \\
\text { engineer/data } \\
\text { management }\end{array}$ & 10.3 & $\begin{array}{l}\text { Non- } \\
\text { Government } \\
\text { Organisation }\end{array}$ & 0.00 & Pacific & 18.3 \\
\hline Education & 2.8 & Student & 10.3 & $\begin{array}{l}\text { Business or } \\
\text { Consultancy }\end{array}$ & 0.00 & $\begin{array}{l}\text { United } \\
\text { Kingdom }\end{array}$ & 4.4 \\
\hline $\begin{array}{l}\text { Communications } \\
\text { Management }\end{array}$ & $\begin{array}{l}3.7 \\
1.8\end{array}$ & $\begin{array}{l}\text { Librarian } \\
\text { Post-Doc }\end{array}$ & $\begin{array}{c}8.6 \\
5.17 \\
\end{array}$ & & & $\begin{array}{l}\text { Australia } \\
\text { France }\end{array}$ & $\begin{array}{l}2.2 \\
1.1 \\
\end{array}$ \\
\hline $\begin{array}{l}\text { Chemistry } \\
\text { Other }\end{array}$ & $\begin{array}{c}1.8 \\
10.1\end{array}$ & & & & & & \\
\hline
\end{tabular}

Motivation for contribution

Respondents were asked about their motivation for participating in DataONE, and

by and large they were interested in capability-building (e.g. extending their networks, gaining experience and learning), but they were also interested in the DataONE goals, which were aligned with their own, and the potential for working on a variety of topics (Figure 2).

Contributions to the project

The greater proportion of the respondents felt they brought discipline-related skills to their participation, namely new insights, practical expertise and breadth of experience (Figure 3). Much lower proportions said they brought technical expertise or institutional links. 


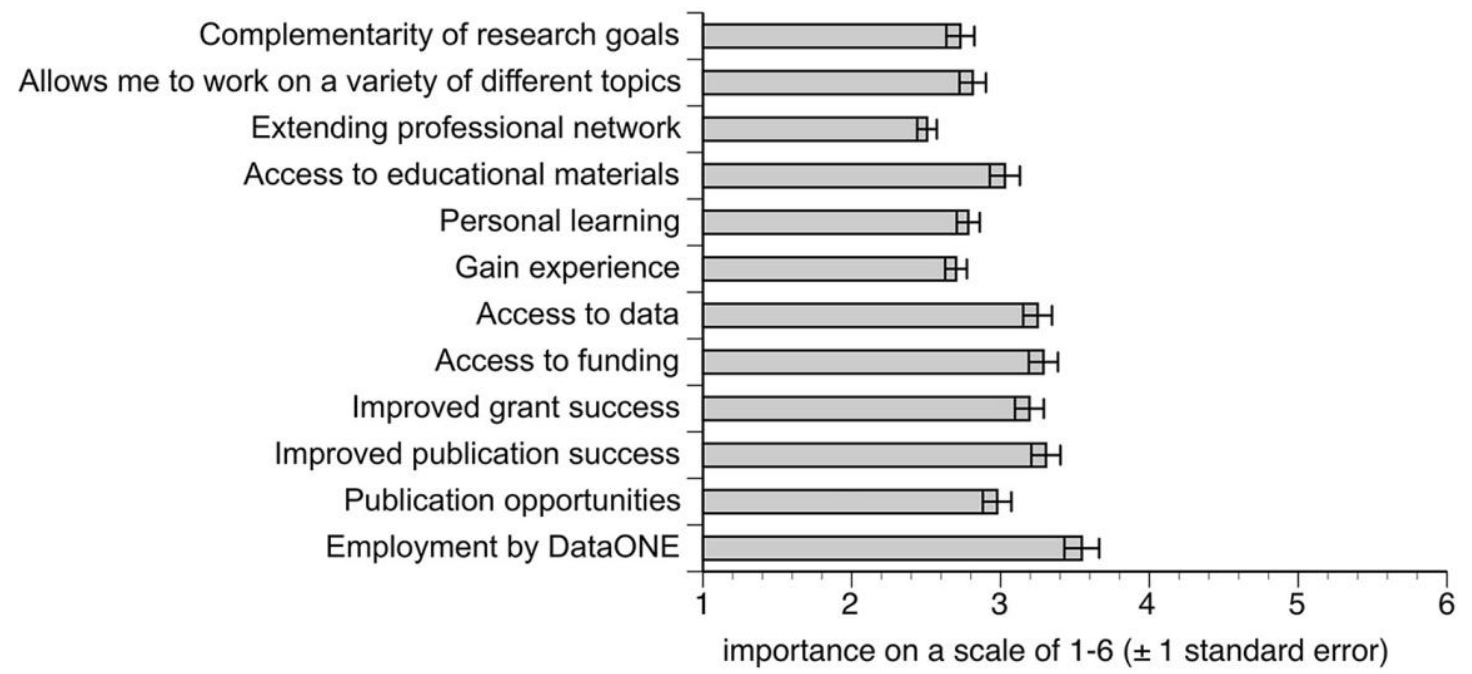

Figure 2: Reported importance of motivations for joining the DataONE working groups.

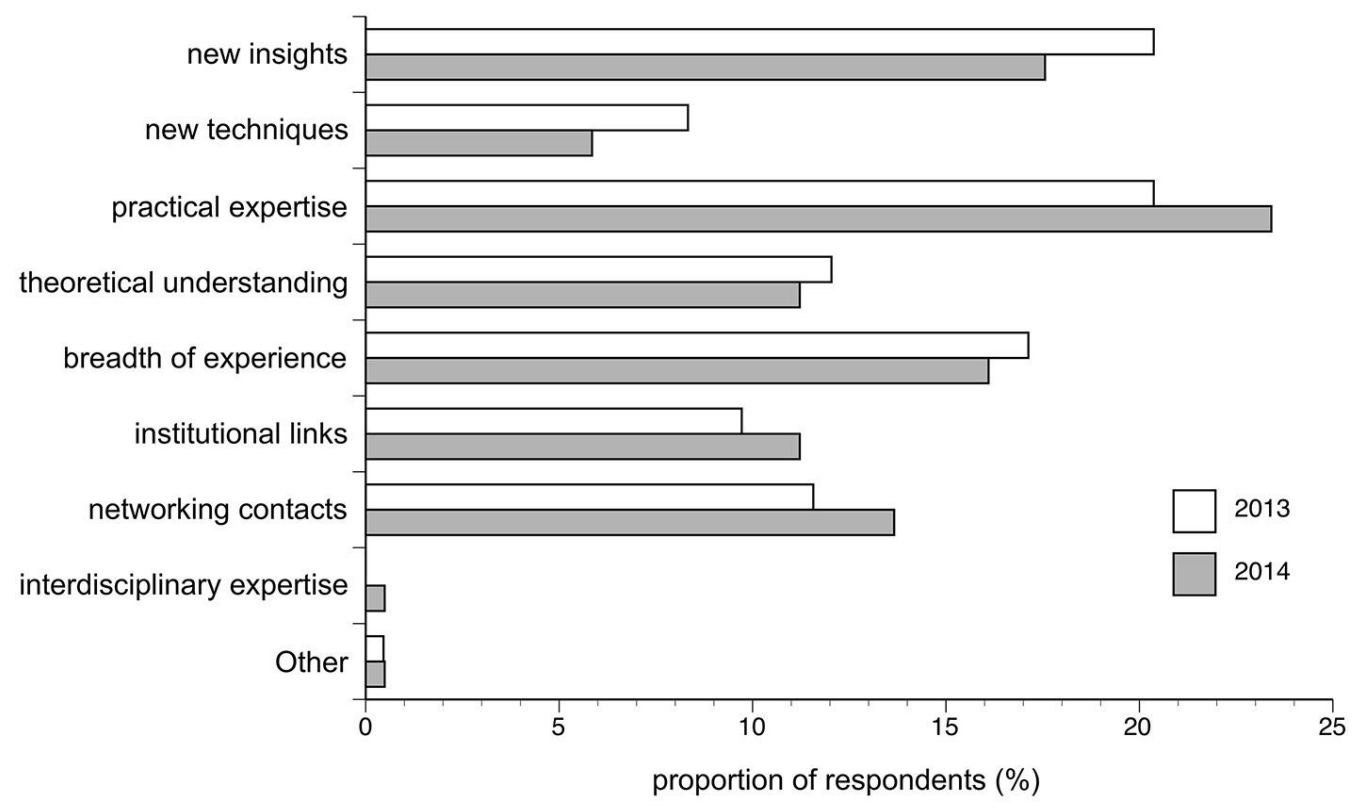

Figure 3: Reported attributes and skills brought to DataONE participation

Communication and group processes

Internal group function was generally well regarded (Figure 4), with strong

evidence of commitment to share and keep group members 'in the loop'. Communication and division of tasks within groups were generally good, but were seen as somewhat less effective across groups (Figure 5). 


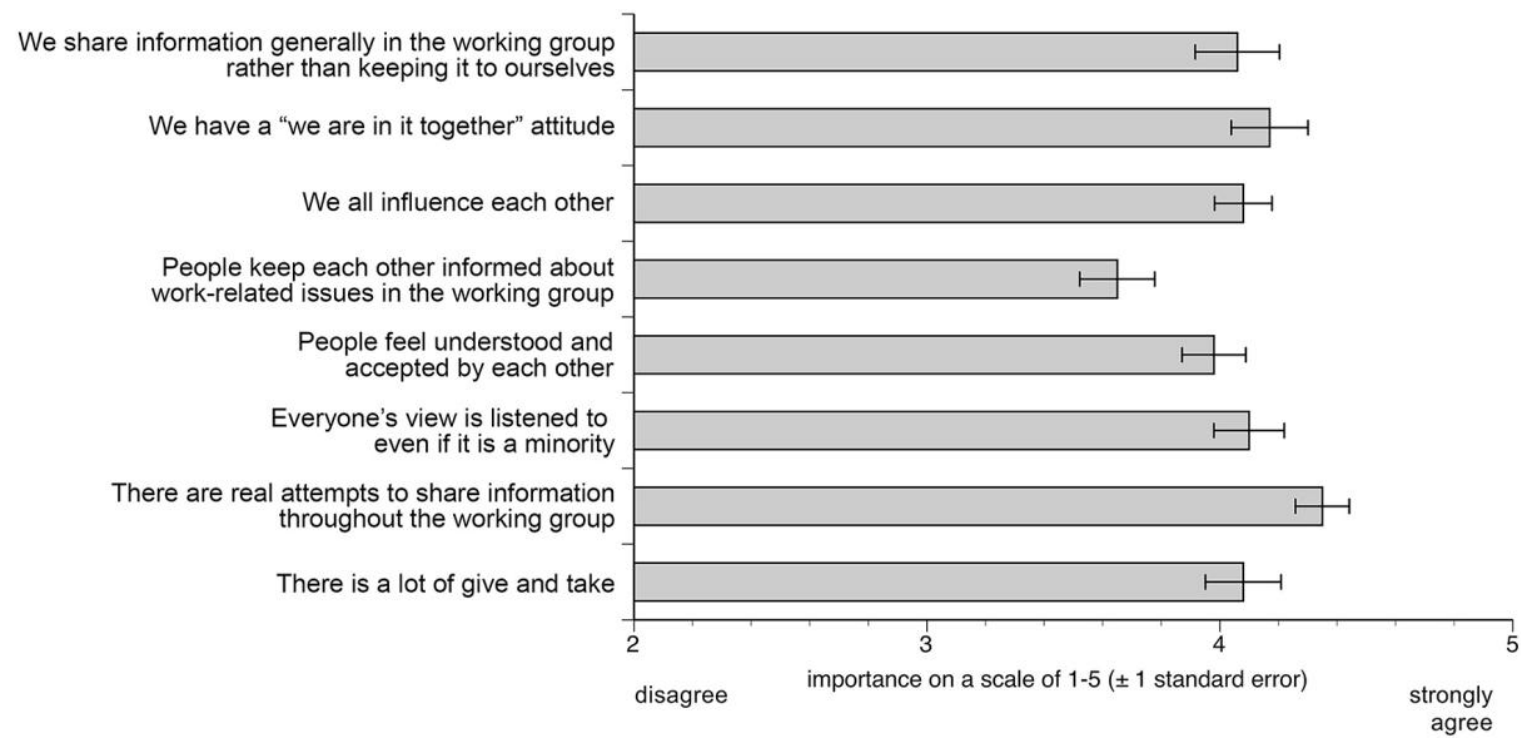

Figure 4: Respondents' perception of internal group behaviors

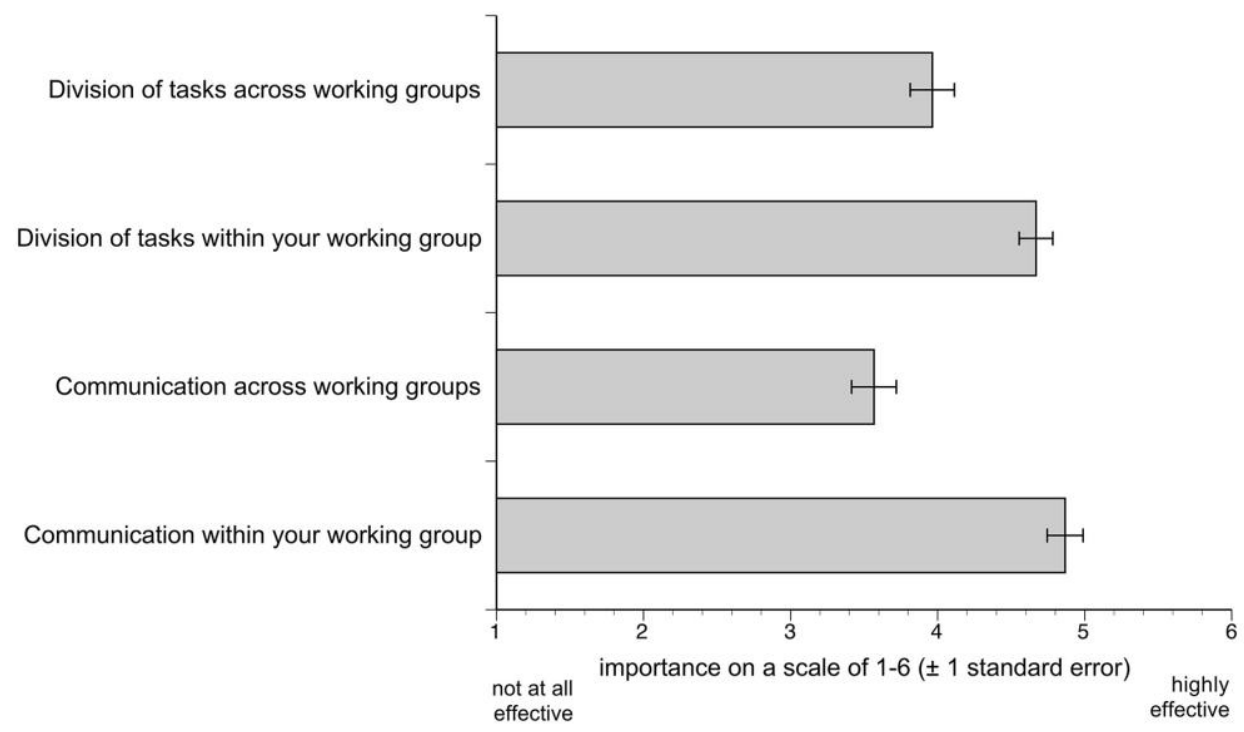

Figure 5: Perceived effectiveness of within and between group interaction (No statistically significant difference in effectiveness between two surveys).

Project success and participant satisfaction

Project success can be considered in different ways: acceptability of outcomes to project sponsors as well as satisfaction and continued participation of project participants. The DataONE project was considered a success by its sponsor, the US National Science Foundation, as evidenced by the decision to renew the project funding (award 14-30508).

Working group members also clearly valued their participation in DataONE (Figure 6). They strongly identified with the goals of DataONE and considered their 
contributions to the project meaningful, satisfying, and enjoyable. This was possibly associated with a feeling of personal control over the tasks they undertook. Of particular note is respondent's perception that they received constructive feedback for their contributions (i.e. the process was not static and they were connected to the larger project).

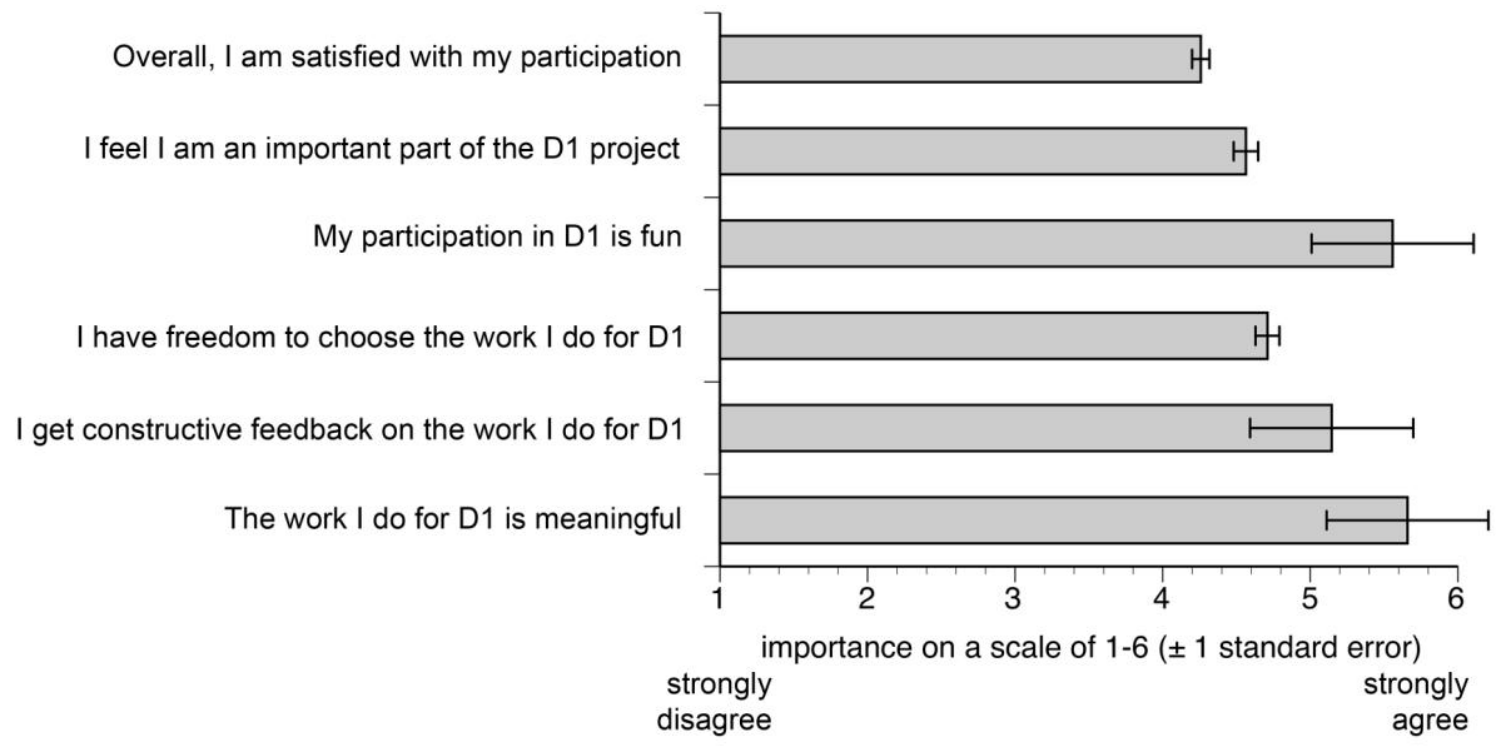

Figure 6: Reported value of participation in DataONE

Exploration of perceptions of group function illustrated some of the reasons why participants felt their contribution had been meaningful and enjoyable. Participants viewed their group's performance as successful ( $4.26 \pm 0.1$ on a 5 point scale), and above average in comparison to other groups, no matter to which group the respondent belonged $(4.02 \pm 0.13$ on a 5 point scale). They felt the work of 'their' group was innovative, had produced valuable outcomes, and the team had worked effectively together (Figure 7). In summary, group members respected their fellow member's contributions and felt the work of their group was of value, the great majority expressing a long-term commitment to the project. 


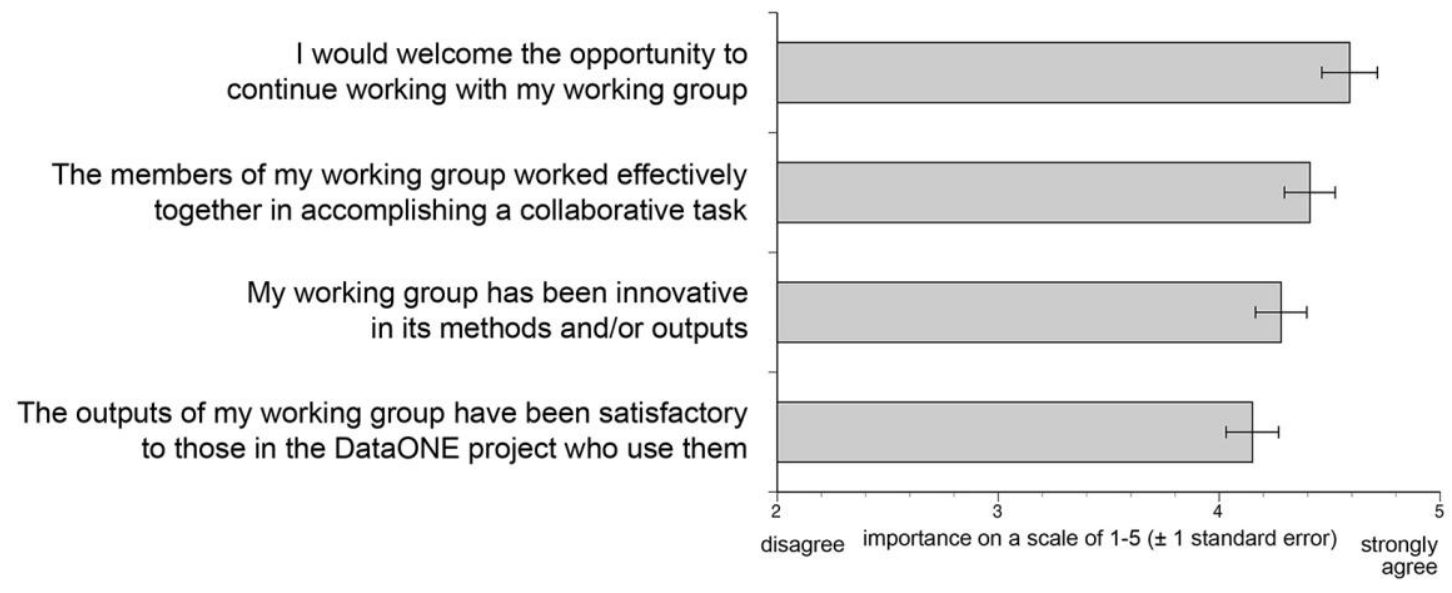

Figure 7: Evaluation of working group performance

Participants were asked what they anticipated they would gain from participation in DataONE (Figure 2; section 5.2) and in what ways they actually benefitted from it (Table 2). There was a significant difference, however, in their response to the latter between 2013 and 2014 that shows a strengthening of opinion (Table 2 and Figure 8). Responses grouped into two: those that increased significantly between surveys and those that decreased. Of those that increased, most were unspecific qualities that increased respondent's capability, such as personal learning and extending professional networks, rather than practical benefits such as improved grant success or access to funding.

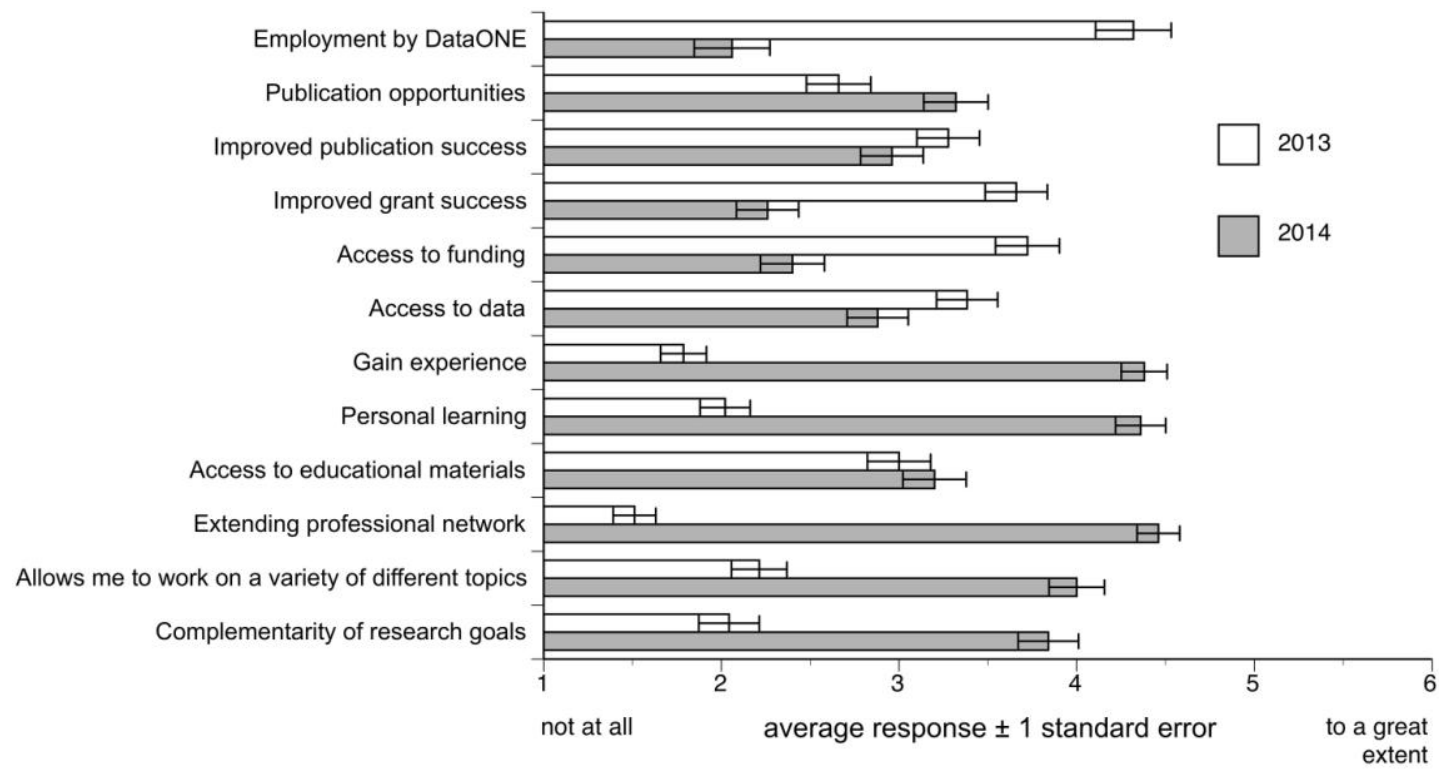

Figure 8: Perceived benefits from participation in 2013 and 2014. 
Table 2: Results of analysis of variance of benefits from participation between 2013 and 2014.

Employment by DataONE

Publication opportunities

Improved publication success

Improved grant success

Access to funding

Access to data

Gain experience

Personal learning

Access to educational materials

Extending professional network

Allows me to work on a variety of

different topics

Complementarity of research goals

\begin{tabular}{cll}
\multicolumn{2}{c}{$\begin{array}{c}\text { Significance of difference } \\
\text { between } 2013 \text { and 2014 }\end{array}$} & $\begin{array}{l}\text { Mean across } \\
\text { both years }\end{array}$ \\
F & Sig. & Mean (se) \\
54.630 & 0.000 & $3.19(0.15)$ \\
6.468 & 0.013 & $2.99(0.13)$ \\
1.566 & 0.214 & $3.12(0.13)$ \\
30.840 & 0.000 & $2.96(0.13)$ \\
26.280 & 0.000 & $3.06(0.13)$ \\
4.148 & 0.044 & $3.13(0.12)$ \\
194.240 & 0.000 & $3.08(0.09)$ \\
133.220 & 0.000 & $3.19(0.10)$ \\
0.614 & 0.435 & $3.10(0.13)$ \\
293.710 & 0.000 & $2.99(0.09)$ \\
63.450 & 0.000 & $3.11(0.11)$ \\
54.420 & 0.000 & $2.94(0.12)$
\end{tabular}

In the last year of a successful 5-year project it is perhaps not surprising that responses to questions related to capability-building would see an increase in importance. The final year of a project naturally lends itself to some degree of reflection over the past. Personal end-of project evaluation and analysis may explain the strong increase from 2013-2014.

\section{ANALYSIS: BOUNDARIES, DISCONTINUITIES AND CONTINUITIES IN THE WORKING GROUP MODEL}

In this section, we interpret the quantitative data presented in Section 5 through

the lens of organisational discontinuity theory, drawing on qualitative data to provide additional insights. We are attempting to better understand the effectiveness of the working group structure for teams engaged in transdisciplinary scientific projects using the case study of DataONE, a successful transdisciplinary project. To do this we posed the following questions:

1) What kinds of discontinuities do transdisciplinary scientific teams face?

2) What kinds of continuities do team members develop that are helpful in addressing these discontinuities?

\section{Boundaries}

Typical of most transdisciplinary scientific projects, a vast range of boundaries are represented in DataONE, such as differences in skills, expertise and organisation. During the study, there were at least ten major disciplinary fields represented as well as eight different professional positions (see Table 1). 
Team members varied in the stage of their career from interns and students to those starting their career, established professionals, and senior professionals (see Section 5.1). There was no evidence, however, that these differences were perceived as problematic and therefore a discontinuity. Instead, members used the boundary to their advantage with more senior members serving as leaders and mentoring those who were more junior. A respondent described what happened this way: "We have also done a series of allowing the most passionate to take the lead and others play supporting roles. It has been interesting to watch the ebb and flow of leaders. The status of these relationships has permitted learning to take place, with confidence, others have taken risks and been supported" (Survey respondent 2014CR73). "We deliberately brought in a few more early-to-mid-career folks who have more enthusiasm and slightly less overall responsibilities, and therefore more time and energy to contribute overall" (2013M37) and "have relied upon the network developed through DataONE for mentoring, idea development, suggestions advice etc. and have shared the same" (2014PM6).

An obvious pair of boundaries was organisational background and place, as nearly all working group participants worked on DataONE only part-time, volunteering their time. Participation was over and above their 'day jobs', and only limited time could be devoted to DataONE responsibilities. The fact that working group members came from different organisations around the world raised challenges related to availability of time to perform work on the project between meetings.

Discontinuities

Recall that our theoretical model posits that boundaries create discontinuities only when they are seen as problematic. The boundaries inherent in the working group model did result in discontinuities as evidenced by the reports of perceived communication challenges (our definition of a discontinuity). A typical comment from a member highlighted the observation that the diversity of disciplines was perceived as problematic as well as an understanding of the benefit derived from the diversity of disciplinary backgrounds: "IMO [in my opinion], the most challenging issue has been learning each other's discipline-related jargon. However, learning the jargon has been a positive and beneficial education experience" (2014CR27).

Although the quantitative data suggested that communication was not a great impediment within the groups, more between groups (Figure 4), respondents were aiming 
high. Indeed, frustration with DataONE communications was the most frequently identified problem with the working group structure, mentioned by $30 \%$ of respondents to an open-ended question. Specifically, members expressed frustration with poor frequency and timeliness of communication, communication difficulties due to the physical distribution of members (as noted above), inter-working group communication, communications with new working group members, and lack of communication or feedback. Representative comments regarding communications issues include "Keeping a regular schedule of communications between in-person meetings" (2014CR19) and "Most of our communications issues related to maintaining communications and momentum in between meetings" (2014CR72). A corollary was the perceived difficulty in scheduling virtual meetings between the semi-annual face-to-face meetings, exacerbated by the need to schedule meetings across multiple time zones.

Concerns about available time were the second largest category of responses to an open-ended question, with $15 \%$ indicating lack of time as an impediment to fulfilling responsibilities to DataONE. Meeting coordination or the low frequency of meetings was mentioned by $14 \%$ of respondents. This comment expressed a typical concern "The biggest challenge is keeping on the same page given infrequent meetings and busy people who can't attend all of them" (2014CR63). In addition to creating their own problems with getting work done, these issues exacerbated the communication problems noted above. Similarly, other commitments could slow responses to emails, leaving the perception that people were not committed to work on DataONE tasks.

Another challenge was maintaining momentum between once or twice yearly face-to-face meetings. Eleven percent of respondents indicated difficulty maintaining motivation or progress outside of direct meetings. Typical comments included, "No one really has much time to spare outside of WG meetings, which makes it hard to keep up impetus and get feedback on intermediate products" (2014CR11); "The ebb and flow of members' availability and ability to give WG needs their attention" (2014CR56); “... so most of our communications issues related to maintaining communications and momentum in between meetings" (2014CR72); and "All WG meetings involved rehashing the same stuff ad nauseum to get us all up to speed and on the same page again" (2014PM32). 
Conversations with working group members in 2012 raised concerns about role certainty, or the lack thereof, vis-à-vis the working group model. Data from interviews and the 2014 surveys reflected the ongoing importance of clarifying working group members' roles and responsibilities. In part, these difficulties reflected varying definitions in some working groups of the group's tasks and priorities, another form of discontinuity. As one survey respondent commented, "I feel that my [working group] does not have a clear focus. New members bring in new priorities that may/may not fit with the group's ongoing activities. Lack of a clear focus makes it difficult for new members to be integrated quickly and effectively" (2014CR71). Another respondent observed, "There is an inherent conflict between gathering colleagues who will help to get certain things done, versus gathering colleagues who will be disruptive or bring new ways of looking at things. I think the structure could be improved by putting greater emphasis on leveraging each person's expertise and institutional position to produce some specific output ... there is a lot of potential locked up in each working group, and some more proactive approaches may be necessary to release more of that potential in useful ways" (2014CR72). Prior research on team science seems to assume that team participants understand their role, but many researchers have noted the importance of knowledge about what other team members know and their roles (e.g. Fiore, 2008), what is sometimes called transactive memory (Wegner, 1987).

Sometimes these problems were attributed to leadership and the lack of clarity about goals and priorities: "Poor leadership and vision. Not sure what our focus is" (2013P52). Typical comments included the lack of "clear short/medium/long term plans" (2014CR52), “... people clearly have different goals as to what they want to accomplish" (2014CR33), and the challenge of "... being able to agree on priority of goals" (2014CR65). Uncertainty about roles and goals also affected some people's ability to determine whether a working group's performance met the expectations of the leadership team. In sum, the difficulty in creating a shared vision served as an overarching discontinuity for at least some members and some working groups.

\section{Continuities}

Despite the numerous perceived discontinuities identified in the surveys, respondents overwhelmingly indicated they were able to mitigate most of these issues. 
When asked to describe how their working group managed the discontinuities described above, responses fell into several broad categories.

The most commonly reported tactics for dealing with perceived discontinuities in DataONE working groups were ways to increase or improve communications; addressing the symptoms of discontinuities without directly addressing the discontinuities themselves. Regular meetings via conference calls, videoconferencing, email communications, written notes shared via online collaboration tools and regular summaries of progress helped overcome the potential discontinuities of infrequent communications and physical distribution of the members. As one participant noted, "We find common times to meet virtually, communicate via other synchronous and asynchronous means" (2014CR29).

The work environment in which DataONE work was performed was another significant factor that helped overcome potential discontinuity. Twenty percent indicated that the tone of the work environment was an important factor contributing to open and uncensored discussions and risk taking. The practice of listening skills, patience, acceptance and development of trust and collegial relationships all contributed to a free and positive flow of ideas and solutions. One respondent commented with regard to their interactions with other members, "The status of these relationships has permitted learning to take place, with confidence, and other(s) have taken risks and been supported" (2014CR73). Others noted, “... the openness of participants and the sense of inclusion and purpose helped me overcome feelings of inadequacy" (2014CR73).

The logistics of working group meetings also provided a locus for shared work, if only temporarily. A particular benefit of the periodic face-to-face meetings was that it gave participants a good excuse to ignore the demands of their regular jobs for a few days to focus on the DataONE project, thus temporarily addressing the time challenges noted above. Being co-located also facilitated some kinds of decision-making and coordination. Not surprisingly, leadership was frequently identified among the ways that DataONE working groups dealt with potential discontinuities. Respondents to the quantitative surveys over two years said they felt in general that they got good feedback from the leadership team (Figure 6). Sixteen percent of respondents indicated that leadership, either at the project or working group level, contributed to prioritisation of 
tasks, integration across and within working groups and mediation when necessary. One respondent observed, "The WG leadership was proactive ... in keeping the WG integrated with other WGs in particular with the LT (Leadership Team) and continually requested feedback and pointing out that the WG needed feedback in order to be successful and move forward" (2014CR56).

Finally, meeting management was also noted as a major method of managing challenges and discontinuities. Ten percent indicated that access to meeting notes, focused effort at face-to-face meetings, flexibility in meeting schedules and virtual meeting technologies were valuable methods of meeting support. Other ways of managing potential discontinuities included working independently, making progress in the absence of group consensus, taking advantage of additional support in the form of dedicated postdoctoral staff, using external contacts and prototyping products.

In summary, as shown in Figures 4 and 7, though there were some lacunae, there was generally strong evidence that continuities were created within working groups. For example, respondents strongly agreed $($ mean $=4.5)$ that there is a real attempt to share information throughout the working group. In fact, all questions measuring this construct had means above 3.75 on a 5-point scale (1=strongly disagree and 5=strongly agree) and most were above 4 . However, there was less evidence that information was shared across working groups (Figure 5). Nor did we note continuities being developed concerning roles (e.g., in the development of transactive memory), which may be related to individual concerns regarding role clarity.

Detecting discontinuities and constructing continuities

Our data suggests that many boundaries existed in the DataONE project and that these boundaries led to discontinuities in the working groups. However, the overall performance of the DataONE project must be considered a success. We have argued that this success is related to the continuities that were developed within the working groups. A key question for the success of the working group model is the motivation for participants to make the extra effort to create continuities to address discontinuities. As noted above, initially working group members were not necessarily clear about the objectives of their respective working groups, which served as an externally imposed discontinuity and yet participants were eager to participate in DataONE. They saw the 
innovativeness and potential impacts of success, and were excited to be part of the project. The project allowed participants to pursue topics that they otherwise could not, thus extending themselves and learning, reflected in many comments. "I have learned much from unofficial opportunities to discuss topics and issues” (2014PM50). “... I've been surrounded by intelligent colleagues from whom I have learned much in technical topics (software development, distributed systems design), domain sciences (DataONE's target disciplines), and social science research" (2014PM36). "I feel I am contributing significantly to the success of the project and learning a great deal on a broad range of subjects at the same time" (2013PM34). "I have learned a lot and have incorporated much of this learning in my work projects" (2014PM34). This shared perception served as an overarching continuity, which made it easier to struggle and work through other discontinuities in order to resolve them.

To summarize our overall analysis, we propose a multi-level process by which continuities are created (or not). As shown in Figure 9, individuals initially perceive discontinuities. As one participant recounted, "We started as strangers and it was overwhelming at first to be in a group of experts (not recognizing my own expertise) ..." (2014CR73). However, individual perception of discontinuities does not have a direct impact on group performance. Only if those discontinuities are cumulated across group members is there an effect on group performance. So for example, if this was the only group member to feel this inadequacy and others did not, there would not be a consequent group level discontinuity. However, if many of the members felt that communication was difficult, a group level discontinuity would be created that then would have an effect on overall group performance (Figure 9).

On the other hand, members may be motivated to focus on the situation and consider alternative actions to deal with the discontinuity, leading to the emergence of new behaviors and expectations, or continuities. This change in behavior begins at the individual level but will not have an effect on group performance unless it is cumulated across members and becomes a new normal of behavior for the group. As the participant explained: "Reaching common understandings has sometimes been challenging, because of the technical issues related to some of the topics. However, as relationships have developed, I've seen us join together to address the topic/problem at hand and build 
products that enabled us to work across disciplines and contribute our unique talents" (2014CR73). Thus, as illustrated in Figure 9, group level continuities must be developed in order to have a positive effect on overall team performance.

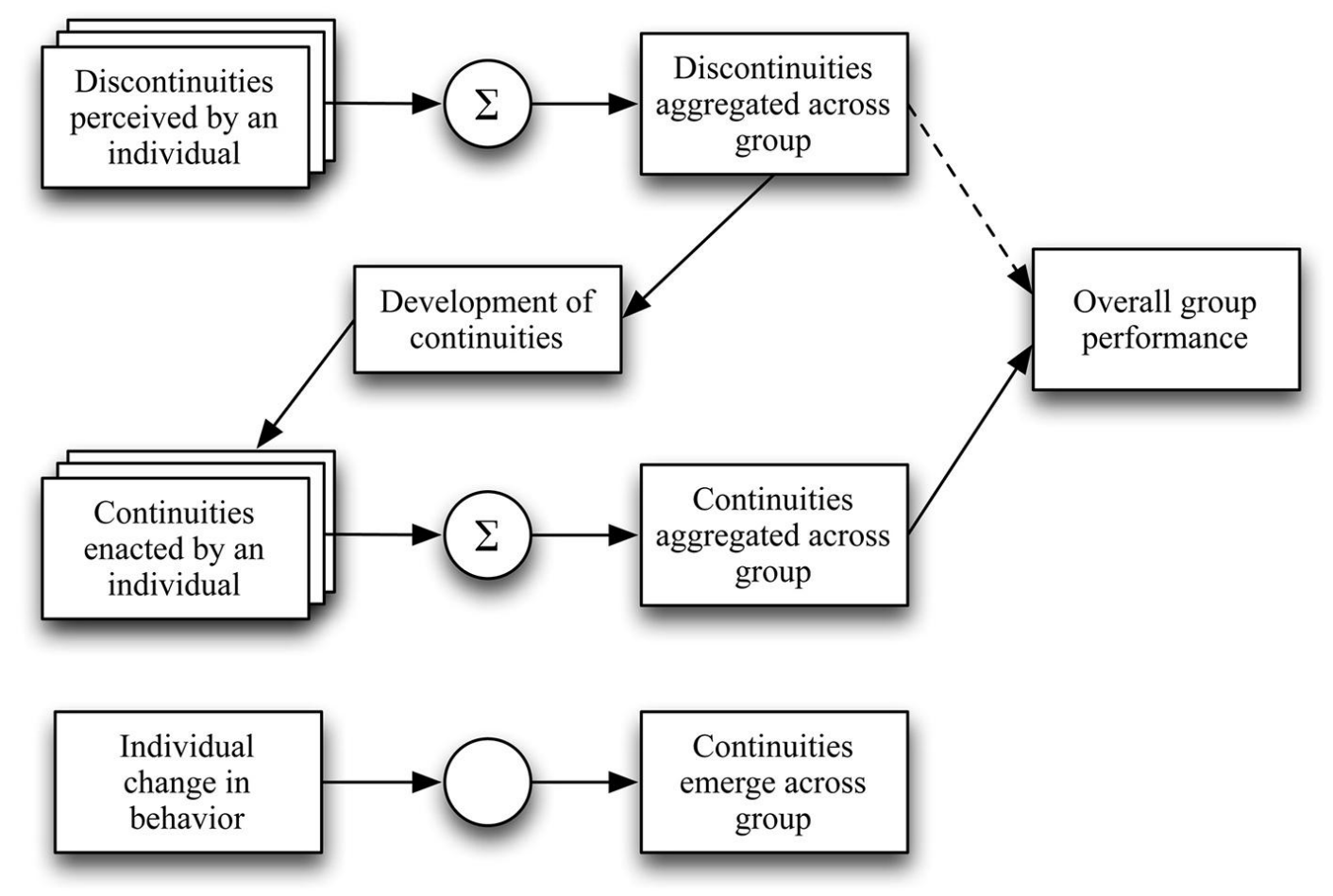

Figure 9: Proposed Effects of Discontinuities and Continuities On Team Performance

Our data suggests that DataONE working group members did create continuities. They learned the terminology associated with different disciplines and came to accept those differences as a positive experience. They reported actively listening to other members and feeling a sense of mutual respect for team members. In addition, they reported instituting regular meetings within their groups to increase or improve communications.

We suggest that several additional factors may have facilitated the emergence of continuities. First, many participants described the importance of the twice-yearly meetings, especially the 'All Hands' meeting in which all working groups participated. These meetings were held over 2-3 days at a neutral location, i.e. everyone left their regular work location and traveled to the overnight meetings. This setting provided time and focus for members to concentrate on DataONE tasks in a way that was difficult when they were at their regular work location. Thus, the challenge created by members' different levels of commitment, an individual discontinuity that might have emerged as 
group level discontinuity, was mitigated by having focused time together at the 'All Hands' meeting.

The structure of the 'All Hands' meeting also reduced the effects of a different discontinuity cited by members, i.e. uncertainty about roles and goals and agreement about task priorities. Prior to the beginning of the meeting, working group leaders met with the PI to establish priorities. Then, the PI explained the stage of the project, what had been accomplished, and priorities for the current meeting to everyone attending the meeting. Most of the time devoted to the 'All Hands' meeting was spent within individual working groups, with members discussing and working on tasks, sometimes in smaller subgroups. The meeting concluded with everyone gathered together to hear brief presentations from each working group about its accomplishments and next steps. This format reduced uncertainty about roles and goals, both for individual working groups and the project as a whole.

Second, our interviews indicate that many DataONE members experienced the working groups as open and collegial. Many spoke of developing trust relationship that facilitated working across disciplines. This type of work environment has been labeled a 'psychologically safe communication climate', i.e. an atmosphere within a group characterized by open, supportive communication and risk taking (Edmondson, 1999). Research has found that a psychologically safe communication climate is related to the production of innovative outcomes in teams comprised of members facing many boundaries, including geography, organisation, national culture and professional background (Gibson and Gibbs, 2006).

Previous research has also pointed to the importance of knowledge brokers or boundary spanners in innovation teams (Bielak et al., 2008; Michaels, 2009). Boundary spanners can translate disparate information across disciplines reducing the negative effects of discontinuities created by disciplinary boundaries. We suggest that librarians may have played this role in DataONE. More than 25\% of DataONE members came from the library science/librarian discipline. As one interviewee with a library science background explained, "Being placed in a new job, a new environment felt normal to me. You just have to do it. You have to ask questions." 
A final factor that may have contributed to the development of group level continuities is a shifting of the goals and expectations of group members over the life of the project. Figure 8 depicts the member responses in 2013 and then 2014 about goals expected from the project. There are statistically significant differences between 2013 and 2014 (Table 4). In particular, the expected benefits shifted from a focus on tangible and immediate gains, such as employment by DataONE, access to funding, and improved grant success in 2013, to longer-term benefits of participation 2014, such as personal learning and extension of professional network. Perhaps the change is reflective and can be explained by the 2014 meeting's heavy focus on celebrating the accomplishments of Phase 1 and the recognition that most the working groups would be dissolved for Phase 2 .

\section{Recommendations}

Working groups can be successful when they are structured well. Several recommendations for the use of working groups in transdisciplinary synthesis can be made based on our findings. These include:

- Make working group members aware that discontinuities are likely to arise, but that they can be addressed with focused attention and a willingness to address them by creating continuities (Watson-Manheim et al., 2012). Research on team science has suggested the need for teams to explicitly plan for their collaboration (e.g. Asencio et al., 2012), so this suggestion provides a specific focus for the planning. Recognition that there may be communication challenges gives members an opportunity to address them proactively. Qualitative data suggest DataONE working group members were successful in this because they welcomed diverse opinions and worldviews. This helped create an environment that fostered creation of continuities.

- Establish shared communication practices that facilitate the creation of continuities (Chudoba et al., 2011), a corollary of our first recommendation. Again, research on team science does emphasize the importance of communication, but not on work practices that constitute continuities specifically. We observed that DataONE was somewhat successful doing this. Working groups created expectations about participation in both the annual face-to-face meetings, and they appeared to be quite effective. Expectations about between meeting participation were less effective, in large part because working group members found it difficult to disengage from their primary work responsibilities.

- Schedule periodic synchronous face-to-face meetings. Face-to-meetings have been found to be important both in research on team science (Hall et al., 2012b; Stokols et al., 2010) and virtual teams more generally. The annual 'All Hands' and individual working group meetings served as a 'heartbeat' (Maznevski and Chudoba, 2000) that fostered personal relationships, kept members informed, and increased committed to 
the project and its objectives. They were also helpful in commanding attention that is otherwise difficult when the 'day job' calls.

- Allow sufficient time for continuities to develop. Transdisciplinary work groups are likely to begin with many discontinuities by virtue of the fact that members represent different disciplines, geographic locations, etc. Developing mutual understanding of how others work (Stokols et al., 2008), one way to build continuities, and building trust take time (Bammer, 2013; Gladstein, 1984), as is recognized in prior research on team science and virtual teams more generally. Providing enough time for members to develop familiarity and trust with each other is likely to enhance the creation of continuities, and more likely to result in innovative practices.

- Ensure the active participation of bridge builders such as librarians who know how to ask questions about disciplines other than their own. Both our quantitative and qualitative data highlighted the important boundary-spanning role (Carlile, 2002) that librarians provided. The importance of boundary-spanners has been discussed in prior work on team science, but with a somewhat different focus. Asencio et al. (2012) suggested the teams identify boundary spanners, but views the role as more of a spokesperson or point of contact for a subteam. Gray (2008) and Boardman and Ponomariov (2014) assign the boundary-spanning role to project leaders or centre PIs. In contrast, the DataONE PI described the role of librarians in DataONE as having developed broad skillsets in addressing research data issues across an array of domains, putting them in a good position to see commonalities and to experiment in adapting solutions from one field to another. They not only helped serve as 'translators' during discussions across disciplines, but they could help devise metadata that crossed disciplines and allowed working groups to identify and catalog shared data. The active engagement of boundary spanners is likely to be especially important when working groups have multiple discipline-based discontinuities.

\section{CONCLUSION}

We examined the working group structure used by the DataONE project. Using the theoretical lens of organisational discontinuity theory and both quantitative and qualitative data, we found that the working group structure can be successful under specified conditions. While discontinuities and problems in communication are likely to arise, creating an environment conducive to the construction of continuities is associated with success in meeting working group goals. Continuities such as openness to diverse opinions, shared communication practices, and active participation of bridge builders such as librarians are most important.

\section{ACKNOWLEDGEMENTS}

We thank the members of the DataONE project for their support for and cooperation with the study, in particular the Principal Investigator, William Michener. 
Special thanks to Amber Budden and Rebecca Koskela for facilitating the survey distribution. DataONE is supported by US National Science Foundation Awards 0830944 and 14-30508.

Alison Specht was supported by the Australian Centre for Ecological Analysis and Synthesis, a facility of the Terrestrial Ecosystem Research Network (www.tern.org.au). Carol Hoover was supported by the US Department of Energy, Contract No. DE-AC5206NA25396.

The authors acknowledge the contribution of Jodie Eason, MIS PhD student at University of Illinois at Chicago, to the initial analysis, and the reviewers for their helpful and constructive comments.

\section{REFERENCES}

Asencio R, Carter DR, DeChurch LA, Zaccaro SJ, Fiore SM. Charting a course for collaboration: A multiteam perspective. Translational Behavioral Medicine 2012; 2: 487-494.

Ashforth BE, Kreiner GE, Fugate M. All in a day's work: Boundaries and micro role transitions. Academy of Management Review 2000; 25: 472-491.

Bammer G. Disciplining Interdisciplinarity: Integration and Implementation Sciences for Researching Complex Real-World Problems: Australian National University Press, 2013.

Beverland MB. Managing the design innovation-brand marketing interface: Resolving the tension between artistic creation and commercial imperatives Journal of Product Innovation Management 2005; 22: 193-207.

Bielak AT, Campbell A, Pope S, Schaefer K, Shaxson L. From science communication to knowledge brokering: The shift from 'science push'to 'policy pull'. Communicating Science in Social Contexts. Springer, 2008, pp. 201-226.

Bietz MJ, Abrams S, Cooper DM, Stevens KR, Puga F, Patel DI, Olson GM, Olson JS. Improving the odds through the Collaboration Success Wizard. Translational Behavioral Medicine 2012; 2: 480-486.

Bjørn P, Ngwenyama O. Virtual team collaboration: Building shared meaning, resolving breakdowns and creating translucence. Information Systems Journal 2009; 19: $227-253$.

Boardman C, Ponomariov B. Management knowledge and the organization of team science in university research centers. The Journal of Technology Transfer 2014; 39: 75-92. 
Börner K, Contractor N, Falk-Krzesinski HJ, Fiore SM, Hall KL, Keyton J, Spring B, Stokols D, Trochim W, Uzzi B. A multi-level systems perspective for the science of team science. Science Translational Medicine 2010; 2: $49 \mathrm{~cm} 24$.

Bresnen M, Edelman L, Newell S, Scarbrough H, Swan J. Social practices and the management of knowledge in project environments. International Journal of Project Management 2003; 21: 157-166.

Carlile PR. A pragmatic view of knowledge and boundaries: Boundary objects in new product development. Organization Science 2002; 13: 442-455.

Chudoba KM, Watson-Manheim MB, Crowston K, Lee CS. ICT-supported meetings in practice. Journal of Organizational and End User Computing 2011; 23.

Cramton CD. The mutual knowledge problem and its consequences for dispersed collaboration. Organization Science 2001; 12: 346-371.

Denzin NK, Lincoln YS. The Qualitative Inquiry Reader. Sage, Thousand Oaks, CA, 2002.

Dixon K, Panteli N. From virtual teams to virtuality in teams. Human Relations 2010; 63: 1177-1197.

Edmondson AC. Psychological safety and learning behavior in work teams. Administrative Science Quarterly 1999; 44: 350-383.

Edmondson AC. The local and variegated nature of learning in organizations: A grouplevel perspective. Organization Science 2002; 13: 128-146.

Falk-Krzesinski HJ, Contractor N, Fiore SM, Hall KL, Kane C, Keyton J, Klein JT, Spring B, Stokols D, Trochim W. Mapping a research agenda for the science of team science. Research Evaluation 2011; 20: 145-158.

Feldman MS, Pentland BT. Reconceptualizing organizational routines as a source of flexibility and change. Administrative Science Quarterly 2003; 48: 94-118.

Fiore SM. Interdisciplinarity as teamwork: How the science of teams can inform team science. Small Group Research 2008; 39: 251-277.

George JM, Jones GR. Towards a process model of individual change in organizations. Human Relations 2001; 54: 419-444.

Ghaye T, Melander- Wikman A, Kisare M, Chambers P, Bergmark U, Kostenius C, Lillyman S. Participatory and appreciative action and reflection (PAAR): Democratizing reflective practices. Reflective Practice 2008; 9: 361-397. 
Gibson CB, Gibbs JL. Unpacking the concept of virtuality: The effects of geographic dispersion, electronic dependence, dynamic structure, and national diversity on team innovation. Administrative Science Quarterly 2006; 51: 451-495.

Gladstein DL. Groups in context: A model of task group effectiveness. Administrative Science Quarterly 1984; 29: 499-517.

Gray B. Enhancing transdisciplinary research through collaborative leadership. American Journal of Preventive Medicine 2008; 35: S124-S132.

Griffin A, Hauser JR. Integrating R\&D and marketing: A review and analysis of the literature Journal of Product Innovation Management 1996; 13: 191-215.

Hall KL, Stokols D, Moser RP, Taylor BK, Thornquist MD, Nebeling LC, Ehret CC, Barnett MJ, McTiernan A, Berger NA, Goran MI, Jeffery RW. The collaboration readiness of transdisciplinary research teams and centers: Findings from the National Cancer Institute's TREC year-one evaluation study. American Journal of Preventive Medicine 2008; 35: S161-S172.

Hall KL, Stokols D, Stipelman BA, Vogel AL, Feng A, Masimore B, Morgan G, Moser RP, Marcus SE, Berrigan D. Assessing the value of team science: A study comparing center-and investigator-initiated grants. American Journal of Preventive Medicine 2012a; 42: 157-163.

Hall KL, Vogel AL, Stipelman BA, Stokols D, Morgan G, Gehlert S. A four-phase model of transdisciplinary team-based research: Goals, team processes, and strategies. Translational Behavioral Medicine 2012b; 2: 415-430.

Hampton SE, Parker JN. Collaboration and productivity in scientific synthesis. BioScience 2011; 61: 900-910.

Hauser J, Tellis GJ, Griffin A. Research on innovation: A review and agenda for marketing science. Marketing Science 2006; 25: 687-717.

Hinds PJ, Mortensen M. Understanding conflict in geographically distributed teams: The moderating effects of shared identity, shared context, and spontaneous communication. Organization Science 2005; 16: 290-307.

Kaufmann R, Tarba S, Sutherland Olsen D. Emerging interdisciplinary practice: Making nanoreactors. The Learning Organization 2009; 16: 398-408.

Lau DC, Murnighan JK. Demographic diversity and faultlines: The compositional dynamics of organizational groups. Academy of Management Review 1998; 23: $325-340$.

Lee CP, Dourish P, Mark G. The human infrastructure of cyberinfrastructure. Conference on Computer-supported Cooperative Work (CSCW). ACM, New York, NY, USA, 2006, pp. 483-492. 
Leonardi PM. Innovation blindness: Culture, frames, and cross-boundary problem construction in the development of new technology concepts. Organization Science 2011; 22: 347-369.

Levina N, Vaast E. Turning a community into a market: A practice perspective on information technology use in boundary spanning. Journal of Management Information Systems 2006; 22: 13-37.

Lindkvist L. Knowledge communities and knowledge collectivities: A typology of knowledge work in groups. Journal of Management Studies 2005; 42: 1189-1210.

Lotrecchiano GR. A dynamical approach toward understanding mechanisms of team science: Change, kinship, tension, and heritage in a transdisciplinary team. Clinical and Translational Science 2013; 6: 267-278.

Mâsse LC, Moser RP, Stokols D, Taylor BK, Marcus SE, Morgan GD, Hall KL, Croyle RT, Trochim WM. Measuring collaboration and transdisciplinary integration in team science. American Journal of Preventive Medicine 2008; 35: S151-S160.

Maznevski ML, Chudoba KM. Bridging space over time: Global virtual team dynamics and effectiveness. Organization Science 2000; 11: 473-492.

Michaels S. Matching knowledge brokering strategies to environmental policy problems and settings. Environmental Science \& Policy 2009; 12: 994-1011.

Michener WK, Allard S, Budden A, Cook RB, Douglass K, Frame M, Kelling S, Koskela R, Tenopir C, Vieglais DA. Participatory design of DataONE: Enabling cyberinfrastructure for the biological and environmental sciences. Ecological Informatics 2012; 11: 5-15.

Mortensen M, Woolley AW, O'Leary MB. Conditions enabling effective multiple team membership. In: Crowston K, Sieber S, Wynn E, editors. IFIP Working Group 8.2 Conference on Virtuality and Virtualization. 236. Springer, Boston, MA, 2007, pp. 215-228.

Nakata C, Im S. Spurring cross-functional integration for higher new product performance: A group effectiveness perspective. Journal of Product Innovation Management 2010; 27: 554-571.

Orlikowski WJ. Knowing in practice: Enacting a collective capability in distributed organizing. Organization Science 2002; 13: 249-273.

Rodrigo A, Alberts S, Cranston K, Kingsolver J, Lapp H, McClain C, Smith R, Vision T, Weintraub J, Wiegmann B. Science incubators: Synthesis centers and their role in the research ecosystem. PloS biology 2013; 11: e1001468. 
Scarbrough H, Swan J, Laurent S, Bresnen M, Edelman L, Newell S. Project-based learning and the role of learning boundaries. Organization Studies 2004; 25 : 1579-1600.

Schneider SC. Managing boundaries in organizations. Political Psychology 1987; 8: 379393.

Schreyögg G, Sydow J. Organizing for fluidity? Dilemmas of new organizational forms. Organization Science 2010; 21: 1251-1262.

Stokols D, Hall KL, Moser RP, Feng A, Misra S, Taylor BK. Cross-disciplinary team science initiatives: Research, training and translation. . Oxford Handbook on Interdisciplinarity, 2010, pp. 471-493.

Stokols D, Misra S, Moser RP, Hall KL, Taylor BK. The ecology of team science: Understanding contextual influences on transdisciplinary collaboration. American Journal of Preventive Medicine 2008; 35: S96-S115.

Vogel AL, Hall KL, Fiore SM, Klein JT, Bennett LM, Gadlin H, Stokols D, Nebeling LC, Wuchty S, Patrick K, Spotts EL, Pohl C, Riley WT, Falk-Krzesinski HJ. The Team Science Toolkit: Enhancing research collaboration through online knowledge sharing. American Journal of Preventive Medicine 2013; 45: 787-789.

Vogel AL, Stipelman BA, Hall KL, Nebeling L, Stokols D, Spruijt-Metz D. Pioneering the transdisciplinary team science approach: Lessons learned from National Cancer Institute grantees. Journal of Translational Medicine \& Epidemiology 2014; 2: 1027.

Watson-Manheim MB, Chudoba KM, Crowston K. Perceived discontinuities and constructed continuities in virtual work. Information Systems Journal 2012; 22: $29-52$.

Wegner DM. Transactive memory: A contemporary analysis of the group mind. In: Mullen B, Goethals GR, editors. Theories of Group Behavior. Springer New York, 1987, pp. 185-208.

Winter SJ, Berente N. A commentary on the pluralistic goals, logics of action, and institutional contexts of translational team science. Translational Behavioral Medicine 2012; 2: 441-445. 


\section{APPENDIX}

Questions posed in surveys throughout the study.

\begin{tabular}{|c|c|c|c|}
\hline Individual Reflection & Group Performance & Commitment & $\begin{array}{l}\text { Situational } \\
\text { variables }\end{array}$ \\
\hline $\begin{array}{l}\text { What were your major } \\
\text { reasons for participating in } \\
\text { DataONE activities? (pick } \\
\text { list plus 'other') }\end{array}$ & $\begin{array}{l}\text { What is your overall } \\
\text { assessment of the working } \\
\text { group's functionality? (picklist } \\
\text { and ranking) }\end{array}$ & $\begin{array}{l}\text { How long have you } \\
\text { been involved with } \\
\text { DataONE? (check box) }\end{array}$ & $\begin{array}{l}\text { In what field did } \\
\text { you receive your } \\
\text { highest degree? } \\
\text { (pick list plus } \\
\text { 'other') }\end{array}$ \\
\hline $\begin{array}{l}\text { What do you think you } \\
\text { have gained out of } \\
\text { participation in your } \\
\text { DataONE Working Group? } \\
\text { (pick list plus 'other') }\end{array}$ & $\begin{array}{l}\text { Compared to other DataOne } \\
\text { working groups, how do you } \\
\text { assess the working group's } \\
\text { performance? (ranking) }\end{array}$ & $\begin{array}{l}\text { In the previous } 12 \\
\text { months, how much } \\
\text { time/effort have you } \\
\text { devoted to DataONE } \\
\text { activities? (picklist plus } \\
\text { other) }\end{array}$ & $\begin{array}{l}\text { What is your } \\
\text { current position } \\
\text { within your } \\
\text { organisation? (pick } \\
\text { list plus 'other') }\end{array}$ \\
\hline $\begin{array}{l}\text { What do you think you } \\
\text { have contributed to } \\
\text { DataONE? (pick list plus } \\
\text { 'other') }\end{array}$ & $\begin{array}{l}\text { What are the primary factors } \\
\text { that contributed to your } \\
\text { working group's success or } \\
\text { otherwise? (open-ended) }\end{array}$ & $\begin{array}{l}\text { During the most recent } \\
12 \text { months' } \\
\text { involvement, what was } \\
\text { your level of } \\
\text { engagement? (ranking) }\end{array}$ & $\begin{array}{l}\text { What is your } \\
\text { current work } \\
\text { sector? (pick list } \\
\text { plus 'other') }\end{array}$ \\
\hline $\begin{array}{l}\text { What role do you play in } \\
\text { your working group? (open } \\
\text { ended) }\end{array}$ & $\begin{array}{l}\text { What is your opinion of the } \\
\text { level of-responsibility, } \\
\text { authority, expertise, } \\
\text { numbers, resources, time, } \\
\text { productivity, common } \\
\text { purpose and morale-that } \\
\text { enables your group to make } \\
\text { an effective contribution? } \\
\text { (ranking) }\end{array}$ & $\begin{array}{l}\text { How engaged do you } \\
\text { feel your fellow group } \\
\text { members are with } \\
\text { DataONE? (ranking) }\end{array}$ & $\begin{array}{l}\text { Where to you come } \\
\text { from? } \\
\text { (state/province, } \\
\text { country) }\end{array}$ \\
\hline $\begin{array}{l}\text { How different or similar are } \\
\text { your fellow group members } \\
\text { in (i) disciplinary } \\
\text { background? (ranking) } \\
\text { (ii) your skillset (ranking) }\end{array}$ & $\begin{array}{l}\text { Would you welcome the } \\
\text { opportunity to continue } \\
\text { working with your working } \\
\text { group? (ranking) }\end{array}$ & $\begin{array}{l}\text { What is the primary } \\
\text { audience for the } \\
\text { products/outputs of } \\
\text { your working group? } \\
\text { (open-ended) }\end{array}$ & $\begin{array}{l}\text { What is your time- } \\
\text { zone? (pick list plus } \\
\text { other) }\end{array}$ \\
\hline $\begin{array}{l}\text { How do you feel about the } \\
\text { value of your work with } \\
\text { DataONE: is it meaningful, } \\
\text { fun, with freedom, you feel } \\
\text { an important part, you get } \\
\text { constructive feedback you } \\
\text { identify with the DataONE } \\
\text { goals (pick list, ranking) }\end{array}$ & $\begin{array}{l}\text { What have been the most } \\
\text { challenging communication } \\
\text { issues for your working } \\
\text { group? (open-ended) }\end{array}$ & $\begin{array}{l}\text { What measures or } \\
\text { indicators would you } \\
\text { use to tell if your } \\
\text { product or input had } \\
\text { impact or success? } \\
\text { (open-ended) }\end{array}$ & $\begin{array}{l}\text { What is your career } \\
\text { stage? (pick list) }\end{array}$ \\
\hline $\begin{array}{l}\text { As a result of your work on } \\
\text { the D1 project, how have } \\
\text { you interacted with other } \\
\text { members of the D1 } \\
\text { project? (pick list plus } \\
\text { comment) }\end{array}$ & $\begin{array}{l}\text { How has your group } \\
\text { managed any of the } \\
\text { communication challenges } \\
\text { identified? (open-ended) }\end{array}$ & $\begin{array}{l}\text { The outputs of my } \\
\text { working group have } \\
\text { been (i) satisfactory } \\
\text { and (ii) innovative } \\
\text { (ranking) }\end{array}$ & $\begin{array}{l}\text { Of which working } \\
\text { group are you a } \\
\text { member? (pick list) }\end{array}$ \\
\hline $\begin{array}{l}\text { My work on the working } \\
\text { group has satisfied my } \\
\text { personal needs (ranking) }\end{array}$ & $\begin{array}{l}\text { How effective has } \\
\text { communication been across } \\
\text { working groups? }\end{array}$ & & \\
\hline
\end{tabular}

